\title{
Intermittent delta waves mimicking inferior myocardial infarction
}

\author{
Osman Can Yontar ${ }^{1}$, Erhan Tenekecioglu', Kemal Karaagac ${ }^{1}$, Ahmet Tutuncu ${ }^{1}$ \\ ${ }^{1}$ Department of Cardiology, Bursa Postdoctorate Training and Research Hospital
}

\section{A B S T R A C T}

Wolff-Parkinson-White syndrome is recognized with existence of delta waves and a short PR interval on electrocardiogram. Delta waves may appear positive or negative deviated on different derivations corresponding to the location of accessory pathway. In some cases, delta waves mimic $\mathrm{Q}$ waves which should be distinguished by physicians.
Access this article online

Website:

http://nepjol.info/index.php/AJMS

Key words: Delta wave, Electrocardiogram, Infarction

\section{INTRODUCTION}

Delta waves may appear positive or negative deviated on different derivations corresponding to the location of accessory pathway. In some cases, delta waves mimic $\mathrm{Q}$ waves which should be distinguished by physicians.

\section{CASE REPORT}

A 45-year-old male patient was examined in his bed at orthopedics ward for postoperative consultation. He had complaints of nausea, dizziness, palpitation and chest pain. Physical exam was normal except fractured ankle which was operated that day. Blood pressure was 100/80, heart rate was 90 beats/minute and there was a mild fever $\left(37,4^{\circ} \mathrm{C}\right)$. Due to young age and urgent surgery, patient did not have a preoperative cardiologist's evaluation; there was only an electrocardiogram (ECG)(Figure 1) which was recorded just before surgery at anesthetist's office. Patient's physician took a recent ECG (Figure 2) and cardiac markers as soon as his complaints started. Cardiac markers were myoglobin $20 \mathrm{ng} / \mathrm{ml}$, troponin I $0,01 \mathrm{ng} / \mathrm{ml}$ and creatinine kinase-MB 2,1 ng/ $\mathrm{ml}$. After comparing the recent ECG with prior one, he recognized Q waves which might be a sign of acute ischemic disease. Patient did not have a history of ischemic heart disease. He had short episodes of palpitation followed by dizziness for more than ten years. His cardiac markers were found negative and a control ECG was free of Q waves just like preoperative
ECG. After a careful evaluation of his ECG again patient was diagnosed as Wolff-Parkinson-White Syndrome with a left sided (presumably posterior-septal) accessory pathway.

\section{DISCUSSION}

Atrioventricular reciprocating tachycardia (AVRT) which has manifest antegrade conduction is associated with pseudoinfarction Q waves on the ECG. ${ }^{1}$ Even if the ECG does not suggest WPW syndrome, a finding of intermittent $Q$ waves should raise the suspicion of latent preexcitation. Diagnostic criteria for ventricular preexcitation are a short PR interval, narrow QRS complex, and presence of delta waves. ${ }^{2}$ These ECG findings reflect more rapid conduction over the accessory pathway compared with the atrioventricular (AV) node, which is the cause of abnormal sequence of ventricular activation. The presence and location of the $\mathrm{Q}$ waves are determined by the vector of the delta wave. In cases in which conduction over the accessory pathway is relatively slow and is similar to the conduction time over the AV node-bundle of His, PR intervals may remain normal, and the QRS widening may be conspicuous. In that case, minor changes in autonomic tone could result in a significant change in the initial component of the QRS complex with subtle change in PR intervals or QRS duration. ${ }^{2}$ If intermittent preexcitation is suspected, physicians may assess the presence of an accessory pathway by simple bedside pharmacological maneuvers. Sinus impulses are 


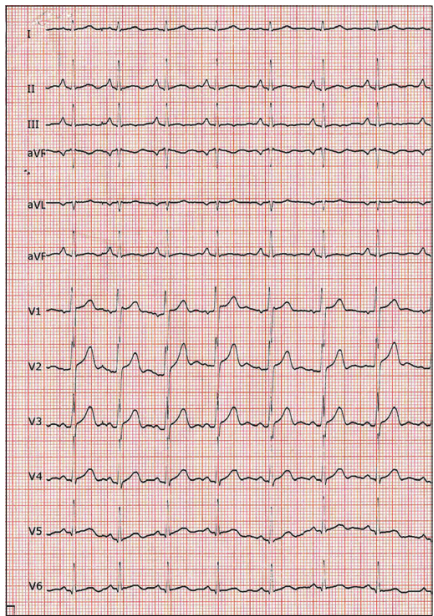

Figure 1: Patient's surface electrocardiogram. Normal sinus rhythm with normal range QRS complex

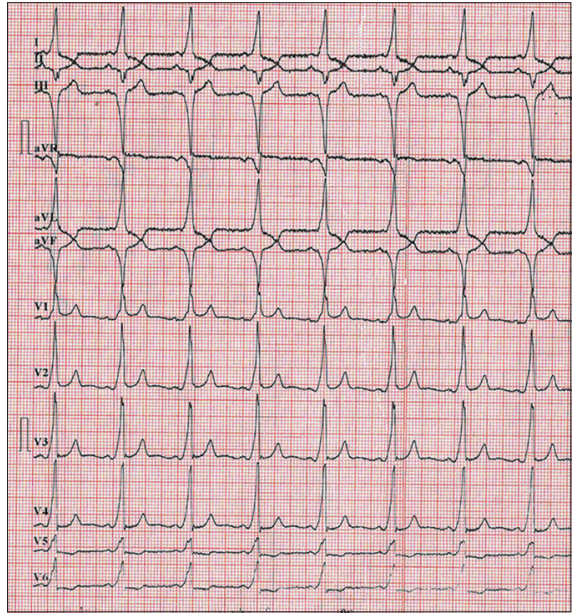

Figure 2: Patients second surface electrocardiogram. Normal sinus rhythm with manifest preexcitation forced to conduct predominantly through the accessory pathway by blocking conduction over the AV node with intravenous adenosine or verapamil. ${ }^{3,4} \mathrm{PR}$ intervals remain relatively unchanged, QRS complexes become broader, and pseudoinfarction $\mathrm{Q}$ waves may become prominent. However, in our case we did not need any pharmacologic interventions because on a few consecutive ECGs delta waves disappeared and reappeared subsequently. If clinically indicated, an invasive electrophysiologic study is needed to evaluate the presence, location, and electrophysiologic characteristics of the accessory pathway prior to catheter ablation. Patient in our case rejected further evaluation.

\section{CONCLUSION}

Careful investigation of surface ECG before and after surgery is vital for physicians who are in charge of postop recovery. Rhythm knowledge and experience could be helpful for ruling out critical diagnosis.

\section{REFERENCES}

1. Ruskin JN, Akhtar M, Damato AN, Ticzon AR, Lau SH and Caracta AR. Abnormal $Q$ waves in Wolff-Parkinson-White syndrome: incidence and clinical significance. JAMA 1976;235: 2727-2730.

2. Al-Khatib SM and Pritchett ELC. Clinical features of Wolff-Parkinson-White syndrome. Am Heart J 1999; 138(3, pt 1):403-413.

3. Belhassen B. Adenosine triphosphate in cardiac arrhythmias: from therapeutic to diagnostic use. Pacing Clin Electrophysiol 2002; 25: 98-102.

4. Garrat CJ, Antoniou A, Griffith MJ, Ward DE and Camm AJ. Use of intravenous adenosine in sinus rhythm as a diagnostic test for latent preexcitation. Am J Cardiol 1990; 65:868-873.

\section{Authors Contribution:}

OCY - Writing, finder of case patient; ET - Writing, English translation; KK - Supervision, correction; AT - Finder of case, english translation.

Source of Support: Nil, Conflict of Interest: None declared. 